\title{
SAMBA E JAZZ ALÉM MAR: A PAISAGEM TEXTUAL URBANA DE PARIS NO PERÍODO ENTRE-GUERRAS COM A CHEGADA DAS MÚSICAS DAS AMÉRICAS
}

\author{
Graziela Mello Vianna
}

\begin{abstract}
Resumo
O presente artigo apresenta resultados preliminares de um projeto de pesquisa pós-doutoral que tem como objetivo principal entender as representações-síntese do Brasil e dos EUA na Europa por meio do jazz e do samba, relacionadas às transformações estéticas ocorridas em Paris e em Lisboa no período entre-Guerras. Transformaç̧̃es que passam pela paisagem sonora urbana, pelas novas danças sociais relacionadas a estas músicas praticadas nos bailes e transformadas em espetáculo nos music halls; pela moda, que libera o corpo feminino para dançar livremente; pelas artes gráficas e na arquitetura que, sob a influência do art déco, "simplificam" as formas românticas art nouveau. Acreditamos que os então novos gêneros musicais possam ser considerados como uma marca das Américas no Velho Continente. Neste artigo, apresentamos resultados parciais da pesquisa ao traçarmos um panorama das transformações na paisagem textual urbana de Paris e da chegada das novas músicas das Américas, observando materialidades que constituem a tessitura das paisagens textuais urbanas da capital francesa: as fachadas art déco e os letreiros dos dancings, os cartazes publicitários dos bailes e dos espetáculos, a moda possivelmente influenciada pelas novas músicas e danças e canções interpretadas por artistas brasileiros e norte-americanos naquele período que fazem alusão a Paris.
\end{abstract}

\section{PALAVRAS-Chave}

Jazz; paisagens textuais urbanas; Paris; período entre-Guerras; samba

\begin{abstract}
Abstratct
We present in this paper a postdoctoral research that aims to understand the representations-synthesis of Brazil and the USA in Europe through jazz, samba and dances originating from these musical genres. We supposed that they are related to the transformations that occurred in the urban textual landscape in the inter-war period. Transformations related to the soundscape, with popular music coming from other cultures; by the new social dances related to these songs practiced in the dances and transformed into spectacle at the music halls; by the new fashion, which allows the female body to dance freely; by the graphic arts and architecture that, under the influence of art deco, "simplify" the romantic art nouveau shapes. We believe that such musical genres can be considered as a mark of the Americas in Europe. So in this text, we will outline the arrival of the new musical genres of the Americas in Paris, observing the transformation in the texture of the urban textual landscapes of Paris from the materialities that make up this texture: Art Deco façades and the signs of the dancings that shelter new music from the Americas; the advertising posters of balls, dancings and music halls; the fashion possibly influenced by the new dances from America, and, finally, the jazz and samba songs composed between the two Worlds Wars that mention Paris.
\end{abstract}

\section{KEYWORDS}

Jazz; inter-war period; Lisbon; Paris; samba; textual urban landscape 


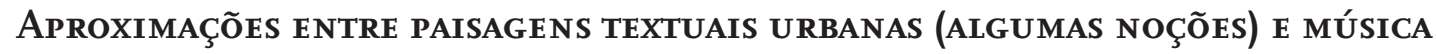 POPULAR}

Sem desprezar os conceitos de texto da semântica, mas optando por trabalhar com uma ideia de texto mais afinada com a proposta de "tudo é texto" (Abril, 2007), entendemos aqui "texto" como "fragmentos de outros textos conectados, (re)combinados para a produção de um novo texto. Deixamos claro nossa opção por uma definição mais fluida, aberta à intertextualidade e à própria relação entre textos" (Vaz, Mello Vianna \& Santos \& Santos, 2017, p. 250). Concordamos com Luchiari que afirma:

em cada época, o processo social imprime materialidade ao tempo, produzindo formas/paisagens. As paisagens construídas e valorizadas da sociedade revelam sua estrutura social e conformam lugares, regiões e territórios. A paisagem é a materialidade, mas é ela que permite à sociedade a concretude de suas representações simbólicas. (2001, pp. 13-14)

Portanto, a partir das noções de texto e paisagem sobre as quais nos debruçamos mais demoradamente em trabalhos anteriores, consideramos as paisagens textuais como "uma articulação de textualidades de relevos diferentes, ou materialidades diferentes, tais como a imagem, o som, a tipografia, a arquitetura, a moda. As textualidades formam a paisagem e a articulação dos relevos mobiliza os sentidos" (Vaz, Mello Vianna \& Santos, 2017, p. 251). Dessa forma, entendemos que a música popular é um relevo que constitui a paisagem textual urbana e, portanto, deve ser investigada como articuladora de sentidos nessa paisagem.

Acreditamos assim que o samba e o jazz vindos das Américas se relacionam com as transformações ocorridas na paisagem textual urbana de Paris (e "reverberadas" em outras capitais europeias, como Lisboa) no período entre-Guerras.

Em 2016, comemorou-se no Brasil o centenário do registro em disco do primeiro samba gravado - Pelo Telefone - de autoria de Ernesto Joaquim Maria dos Santos, conhecido como Donga, lançado no carnaval de 1917. No mesmo ano e mês (fevereiro de 1917), nos Estados Unidos é gravado e lançado pelo selo Victor o primeiro compacto de jass (segundo a grafia da época) com duas canções: Livery Stable Blues e Dixieland Jass Band One-Step.

O samba, a partir principalmente do final da década de 1930 e início da década de 1940, por questões técnicas (Tatit, 2004; Tinhorão, 1981), culturais (Muniz Sodré, 1998) ou políticas (Jambeiro, 2004) se torna uma representação simbólica do Brasil, assim como o jazz pode ser considerado como uma marca da cultura norte-americana anterior ao rock n'roll (Hobsbawm,1990). Alguns estudos já foram desenvolvidos no sentido de tais discussões em torno do samba e do jazz como elementos da cultura popular que conformam uma suposta identidade coletiva em seus países de origem. Em uma visada distinta de tais pesquisas anteriores, na pesquisa que desenvolvemos privilegiamos uma reflexão sobre tais gêneros musicais no continente europeu, como eles são assimilados pela escuta estrangeira e entendidos como representações dessas supostas identidades coletivas, antes mesmo de serem aceitos no Brasil e nos EUA. 
Os musicistas brasileiros e americanos atravessam o oceano no período entre-Guerras e as chamadas novas danças das Américas (o samba, o Charleston, o fox trot, o lindy hop e as swing dances, dentre outras) associadas a esses gêneros musicais se fixam em Paris naquele período. Ao viajarem para a Europa, os sambistas e os músicos de jazz assimilam outras influências ao mesmo tempo em que alteram a paisagem local.

O jazz francês é conhecido mundialmente. O "jazz manouche" foi criado na França a partir do jazz americano. O samba, por sua vez, também se altera ao passar pela Europa, incorporando influências da modinha portuguesa e do jazz. Alfredo da Rocha Viana Filho, o Pixinguinha, músico popular historicamente reconhecido no Brasil, tinha como instrumento principal a flauta. Depois dos encontros com os músicos de jazz na capital francesa na viagem que fez junto com o seu grupo Os Batutas à Paris em 1922, ele volta ao Brasil tocando outro instrumento: o sax. No sentido inverso da troca de influências, uma canção popular brasileira, Boi no Telhado, cuja a autoria é atribuída José Monteiro, um dos Batutas, impressiona Darius Milhaud em uma viagem ao Brasil, antes mesmo da passagem dos Batutas por Paris. Ao retornar a Paris, ele compõe Le Bœuf sur le toit (tradução literal para o francês do título brasileiro) para um balé-concerto que Jean Cocteau estava concebendo em 1919. Em dezembro de 1921, é inaugurado o célebre dancing Bœuf sur le Toit para atrair o Grupo dos Seis' (Les Six, no qual Darius Milhaud se incluía), que vem a se tornar um refúgio de jazz bastante conhecido até os dias atuais. Do nome do dancing, surgiu a expressão "faire un bœuf" ("fazer um boi") corrente no meio musical francês para designar uma jam session.

Buscaremos assim entender neste artigo as transformações na paisagem textual urbana de Paris a partir das materialidades que compõem essa tessitura: as fachadas e os letreiros dos dancings, os cartazes publicitários dos bailes, dos dancings e dos espetáculos dos music halls², a moda possivelmente influenciada pelas novas danças e canções populares produzidas no período. Para tanto, traçaremos um breve panorama de tais transformações e de acontecimentos que marcam a fixação de tais gêneros musicais na Europa naquele período.

\section{SAMBA E JAZZ NA EUROPA}

Se atualmente a intolerância racial e a xenofobia estão na pauta das discussões na França, no início do século XX, a capital francesa acolhia com alegria e receptividade o outro, o estrangeiro vindo de países distantes. Evelyne Cohen, a respeito de Paris nos anos 1920, observa que:

\footnotetext{
'Berenice Menegale descreve o Grupo dos Seis da seguinte maneira: "Erik Satie, Stravinsky, Picasso e outras personalidades influenciavam todo o ambiente parisiense dos anos 1920. Jean Cocteau - poeta, artista a serviço tanto da literatura quanto do cinema, do balé, da música, do teatro - apadrinhava em Paris uns jovens compositores naqueles "anos loucos". Eram Georges Auric, Louis Durey, Arthur Honegger, Darius Milhaud, Germaine Tailleferre, Francis Poulenc - que um jornalista chamou de "Les Six" (Os Seis). A denominação - alusiva aos "Cinco" russos - se consagrou e passou para a história da música, apesar de não existir realmente um grupo. Aos "Seis" coube então representar na França a tendência à recusa do impressionismo, assim como a utilização de elementos do "music hall" e do jazz (ver http://www.filarmonica.art.br/ educacional/obras-e-compositores/obra/concerto-para-piano/).
}

2 Encontramos em nossa pesquisa preliminar alguns cartazes e fotos dos dancings do período pesquisado. No entanto, como não somos detentores dos direitos de autor de tais imagens, não as utilizaremos aqui. 
Paris, cidade da cultura, cidade dos prazeres é um terreno fértil onde se espalha com alegria as modas mais diversas, exóticas, negra e russa, principalmente. Tais modas revelam uma certa receptividade aos costumes, aos gostos do estrangeiro, ao mesmo tempo em tais modas favorecem a expressão de tais estrangeiros no mundo parisiense. (Cohen, 1999, p. 12)

O anúncio dos shows em Paris em 1922 de Pixinguinha e d'Os Batutas, dentre eles, o próprio Donga (compositor do primeiro samba gravado) é um exemplo do acolhimento do gênero musical brasileiro e das possíveis representações do samba e do Brasil na capital francesa:

o sr. Duque organizou para esta ocasião uma festa esplêndida. Um jazz quente dirigido pelo sr. Bouvier e a curiosa orquestra "Os Batutas" (grifo nosso), que o diretor do Shéhérazade foi até o Brasil buscar vão conduzir a dança após o jantar. Vai se dançar a "Semba", nova dança da moda e o divertido black-step ou passo de negro, assim como a ciranda brasileira. E, finalmente, à meia noite: grande baile! (Jornal Comoedia, 25 março de 1922, citado em Bastos, 2005, p. 185)

O samba (ou semba) - apresentado como "dança da moda" - e o jazz se misturam no anúncio. Reforça-se o exotismo (acompanhado pela "curiosa orquestra Os Batutas") e a valorização da origem dos Batutas como uma orquestra genuinamente brasileira, buscada no nosso país pessoalmente pelo diretor do dancing. A partir de seu estudo sobre esta passagem do grupo por Paris, Bastos conclui que

a campanha - houve aqui, sim, uma campanha - para promover Les Batutas em Paris teve início em meados de fevereiro, muito próximo à sua estréia, e durou até o último dia de junho. Sua principal característica foi o desenho da musicalidade do grupo como algo único (unique) em relação à identidade étnico-nacional, construída como indubitavelmente brasileira, e a respeito da formação orquestral, esta identificada por um gênero bastante percussivo (o samba)... Escolhendo o samba como marca, a campanha livrou o grupo da possibilidade de associação com o tango argentino e sua ligação com o mundo dos brancos, o que a opção pelo maxixe poderia provocar. Também, essa escolha enfatizou o espírito nouveau da música executada pelo grupo. Com as opções pelo universo do jazz como polo de contraste e do ritmo-percussão como território do encanto (gaieté) do grupo, a campanha inseriu a sua musicalidade no plano mundial (não mais restrito à América Latina), lar do poderoso Outro, e aproximou-a da música africana, considerada pelo público em geral (e também por muitos musicólogos já) extremamente rítmica e percussiva - Les Batutas, Duque, Guinle e Müller queriam projetar a ideia de um Brasil grande, que se encontrava no centro do mundo, e de uma música popular - negra, sim -, no âmago de toda a sua grandeza. (Bastos, 2005, p. 184) 
Assim, a musicalidade do samba e de outros gêneros provenientes do outro lado do oceano é apresentada na Europa como uma representação dos seus países e das suas matrizes culturais "exóticas":

Simetricamente, as danças extra-europeias abordaram a velha Europa depois da Primeira Guerra Mundial na esteira dos espetáculos e teatro de revista apresentados no music hall e por iniciativa de algumas escolas preocupadas em diversificar o repertório comum de danças ensinadas desde o início do século. A literatura específica dos "Guias para aprender à dançar (1992)" traduz o desejo de incorporar essas novas danças vindas de longe, valorizando sua origem exótica com qualificações misteriosas para o neófito: "Scottish espanhol, maxixe brasileiro, valsa hesitação, variedade Levitte, Boston inglês, one step, tango, paso doble, java, maxixe argelino, boston americano, Triboston ondulado, Boston simples, fox trot..." Entre as fichas de identificação das danças que serão incluídas nos guias a partir de 1950, a origem geográfica e humana é descrita quase sistematicamente, utilizada com a intenção certificar a autenticidade do exotismo, fazendo uso de simplificações da história e de interpretações fantasiosas. Assim, observa-se nessa literatura a permanência da associação da dança, à uma origem geográfica, a um povo, aos costumes... (Dorier-Apprill \& Apprill, 2000, pp. 12-13)

Os guias de dança sintetizam identidades coletivas nacionais, simplificando a diversidade com denominações e descrições redutoras acerca da origem de cada dança, valorizando principalmente o exotismo dos países situados além do Atlântico. Concordamos com Jacotot (2013), em sua pesquisa sobre o imaginário das danças sociais em Paris no período entre guerras, que defende que

a dança, assim como a música, constitui um meio privilegiado de expressão e de difusão da ideia de nação, mesmo se as trocas culturais estudadas não são de forma alguma ligadas ao intervencionismo cultural dos Estados. No entanto, a questão da identidade nacional é um tema central nos discursos dos atores e dos observadores de tais intercâmbios transatlânticos. Apesar da diversidade dos contextos de criação de tais formas musico-coreográficas, todos os gêneros que chegaram à Europa entre os anos 1910 e os anos 1930 se cristalizam de maneira semelhante e no mesmo período nos diferentes territórios. (Jacotot, 2013, p. 163)

Assim, ainda que tais gêneros populares de música/dança ainda não tivessem legitimação nos seus próprios países, considerados pelas elites locais como "música barata, sem nenhum valor"3, ao viajarem para a Europa, tais gêneros conformam identidades nacionais e são apresentados como "a" música nacional de tais países.

\footnotetext{
3 Paráfrase do samba Pra quê discutir com madame? (composição de Haroldo Barbosa e Janet de Almeida de 1945).
} 
A dança em par se torna competição esportiva na Europa no período entre guerras. Além das danças já tradicionais (como a valsa lenta e a valsa veneziana), os passos são codificados para padronizar os critérios de julgamento nas competições e diversas danças das Américas são consideradas nessa codificação. Dentre elas, o tango, a rumba, o samba (inicialmente chamado de maxixe ou tango brasileiro nos guias de dança, passa finalmente a ser nomeado como samba), o quick step (ou foxtrot) e o jive (ou, mais tarde, lindy hop) associadas ao jazz (Dorier-Apprill \& Apprill, 2000), o que comprova a inserção das danças e dos gêneros musicais das Américas no continente europeu, para assombro e desgosto das elites americanas, brasileiras e argentinas auto-exiladas em Paris que tiveram que se dobrar à nova moda parisiense (Jacotot, 2013).

$\mathrm{Na}$ Paris da década de 1920, a arquitetura da cidade é alterada pelos novos dancings, onde se pode dançar ao som do exotismo das Américas na década de 1920 e pela inauguração de novos music halls onde tais gêneros musicais entram em cena como um grande espetáculo: o teatro de revista. Em contraposição aos tradicionais bals musettes franceses do século XIX e início do século XX, onde a valsa ou a polca predominavam, a novidade recente da luz elétrica no lugar da iluminação a gás é imediatamente incorporada pelos letreiros luminosos dos dancings, indicadores da modernidade desse tipo de lugar que acolhe o jazz e outras músicas das Américas:

\footnotetext{
"os dancings - esta é a mais forte e audaciosa inovação trazida aos nossos costumes; ela data de 1921", escreve Maurice Sach -, modestos ou suntuosos, eles se multiplicam. Os cafés de Montparnasse que drenam a vida boêmia parisiense se americanizam, eles acrescentam um grill... e um dancing, como La Rotonde ou la Coupole. Ao redor, pululam as boates de jazz: le Select, le Dingo, Le Jockey's... São construídos também estabelecimentos novos e luxuosos como o Apollo, o Perroquet, o Shéhérazade. [este último onde Pixinguinha e Os Batutas se apresentaram quando chegaram a Paris] (Garandeau,1998, p. 103)
}

A identidade espacial do dancing é assim inicialmente visual e externa, a fachada e os luminosos se tornam signos decifráveis para os notívagos (Jacotot, 2013). Em tais fachadas, brilham os nomes dos estabelecimentos, que também diferem dos nomes dos tradicionais bals musettes ${ }^{4}$. Se tais bailes tradicionais usualmente faziam uma bucólica referência à natureza (Bal du printemps, Bal du jardim, Bal du arc en ciel, etc), os novos dancings fazem uso de temáticas diversas tais como: nomes com o possessivo inglês's (Camil's Bar, Pigall's, Zeli's) que se tornam marca do bom gosto parisiense; nomes de clubes de jazz de Nova York (Cotton Club, Le Savoy, etc); referências aos territórios de onde a música é proveniente (La Cabane Cubaine, Rio Rita, etc); exotismos vindos do Oriente (le Bagdad, Shéhérazade, Le Lotus); nomes de animais (Chauve souris, Poisson d'Or) e sobretudo de pássaros (Le Perroquet, Le Canari) (Jacotot, 2013). A decoração dos dancings naquela altura também é moderna para a época, exaltando o exotismo, principalmente do Oriente. Percebem-se então importantes transformações dos códigos

\footnotetext{
${ }^{4}$ Bailes populares na França desde o século XIX.
} 
estéticos predominantes: é o início do estilo art déco, que ao valorizar as linhas retas e sóbrias, simplifica os "bordados" das antigas fachadas art nouveau. Utilizam-se materiais industriais e uma mistura de materiais insólitos, como madeiras exóticas, couro de arraia, dentre outros (Jacotot, 2013). Os cartazes que anunciam os novos dancings ou os music halls onde são apresentadas as novas danças das Américas também fazem uso dos traços retos, inspirados pelos cubistas e pelo estilo art déco.

"Josephine" apresentada no cartaz de Paul Colin é Josephine Baker, uma americana que foge da tensão racial dos Estados Unidos e adota Paris como o seu novo "país", dada a receptividade da cidade. Ela declara em 1929: "eu sou uma francesa negra. E eu amo Paris, eu adoro Paris. O país de vocês é o único em que se pode viver tranquilamente" (Baker, citada por Cohen, 1999, p. 12).

Assim, além dos dancings, a música das Américas se torna espetáculo nos music halls, também publicizados pelos cartazes de Paul Colin e outros artistas, que se tornam célebres com seus cartazes art déco tais como Mercier, Cassandre e Carlu. Todos esses têm em comum na produção dos cartazes a valorização do cubismo, da experimentação de novas tipografias e da técnica do aerógrafo, e das novas máquinas que começam a fazer parte da paisagem urbana, se alinhando assim também ao movimento futurista (Bachollet \& Lelieur, 1992).

A moda, principalmente feminina, se liberta dos espartilhos. "A moda com uma linha simplificada, se impõe com o Charleston, com os cabelos à la garçonne, com os cocktailsbar" (Weill, 2013, p. 27).

Os vestidos tornam-se retos. A marcação das cinturas cai e o comprimento das saias e vestidos diminui, quase deixando à mostra os joelhos, favorecendo a liberdade de movimentos e, consequentemente as novas danças como, por exemplo, o Charleston com tempos mais acelerados que a valsa ou as demais músicas dos bailes tradicionais.

De acordo com Garandeau (1998), com a ausência dos homens no período da Primeira Guerra Mundial, as mulheres assumem um lugar de protagonistas das transformações ocorridas no período logo após a guerra:

as novas danças se apressam a invadir as salas de bailes, salas cujo público foi profundamente transformado pela guerra. Na falta de homens, as muIheres assumiram responsabilidades que que lhes dão uma independência nova. A roupa e a silhueta feminina traduzem esta liberdade de ação e de movimento. Corte de cabelo "à la garçonne", espartilhos jogados fora, saias encurtadas, liberando o jogo de pernas: tantos detalhes que certamente tem relação com as danças da moda. Bem decididas à esquecer os horrores da guerra, as mulheres são, com efeito, um dos principais motores da vontade de festa que sopra sobre os anos 1920, era de ouro do jazz tanto no palco, com os teatros de revista e comédias musicais, como ao baile e sua mais recente metamorfose, o dancing. (Garandeau, 1998, p. 102)

A nova paisagem sonora predominante nos dancings também é inovadora e exótica, vem das distantes Américas, passa pelas capitais da Europa e chega a Paris. Como defende Evelyne Cohen, 
Paris se encontra vitoriosa e em luto com o final da Primeira Guerra Mundial. [A década de 1920] Trata-se de uma década marcada pelos "loucos anos" (les années folles), anos trepidantes de vida de criação, anos de mutação e de reconstrução.(...) Entre as principais capitais do mundo, as comunicações se aceleram, os intercâmbios políticos, econômicos e culturais se multiplicam. Paris envia os seus "embaixadores", suas mensagens para o mundo inteiro. As trocas e a emulação entre as grandes cidades são intensas (Cohen, 1999, p. 15)

Assim, tais intercâmbios acontecem com as Américas, conforme já afirmámos, mas também com outras cidades europeias, como por exemplo, Lisboa. Na capital portuguesa os night clubs, (também chamados de dancings clubs ou simplesmente clubes) criados com a passagem dos músicos pela cidade rumo a Paris correspondem aos dancings franceses na década de 20. Jazz bands colocam os frequentadores para dançar o Charleston e as swing dances em ritmos por vezes alucinantes. Registros de jornais (Figura 1) mostram um pouco do novo modismo.

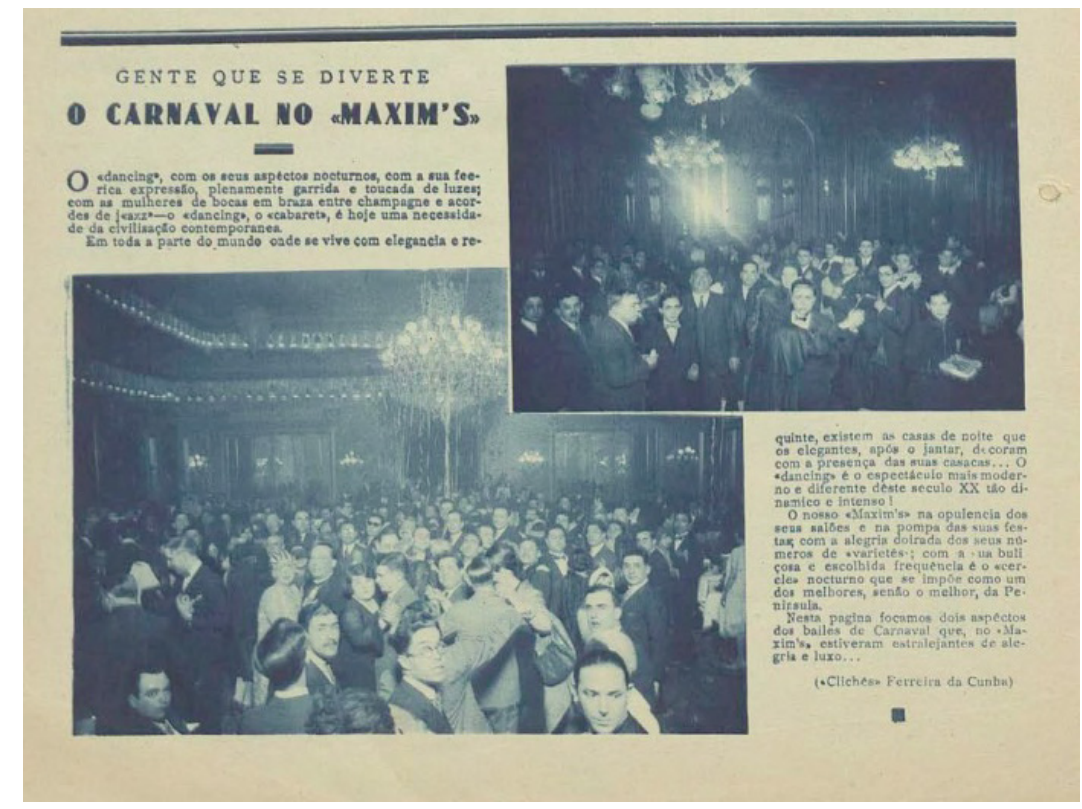

Figura 1: Fotorreportagem sobre o Carnaval no Maxim's

Fonte: Teixeira, 2012, p. 35

Lisboa era um porto de chegada dos músicos provenientes das Américas. Os night clubs, onde se dançavam as novas danças na década de 1920, se tornaram o que poderíamos considerar como "territórios livres" na década de 1930: lugares de encontros políticos clandestinos, após o início da ditadura salazarista em 1932, lugares de uso de drogas ilícitas sem restrições e de prostituição.

Até aqui traçamos um panorama da transformação de diversas materialidades da paisagem textual urbana, principalmente em Paris. A seguir, trataremos mais especificamente de materialidades sonoras: as canções produzidas no período que fazem 
referência a Paris no período entre-Guerras interpretadas por artistas brasileiros e norte-americanos.

\section{Os Batutas ou “Les Batutas" em Paris}

Em 1919, Pixinguinha se junta a outros artistas populares e constitui os Oito Batutas, que se autodenominavam orquestra típica e executavam inicialmente um repertório folclórico. O figurino do grupo à época da sua criação também condizia com tal repertório: os músicos apresentavam-se sempre com trajes típicos de sertanejos nordestinos (do Nordeste do Brasil) (Figura 2).

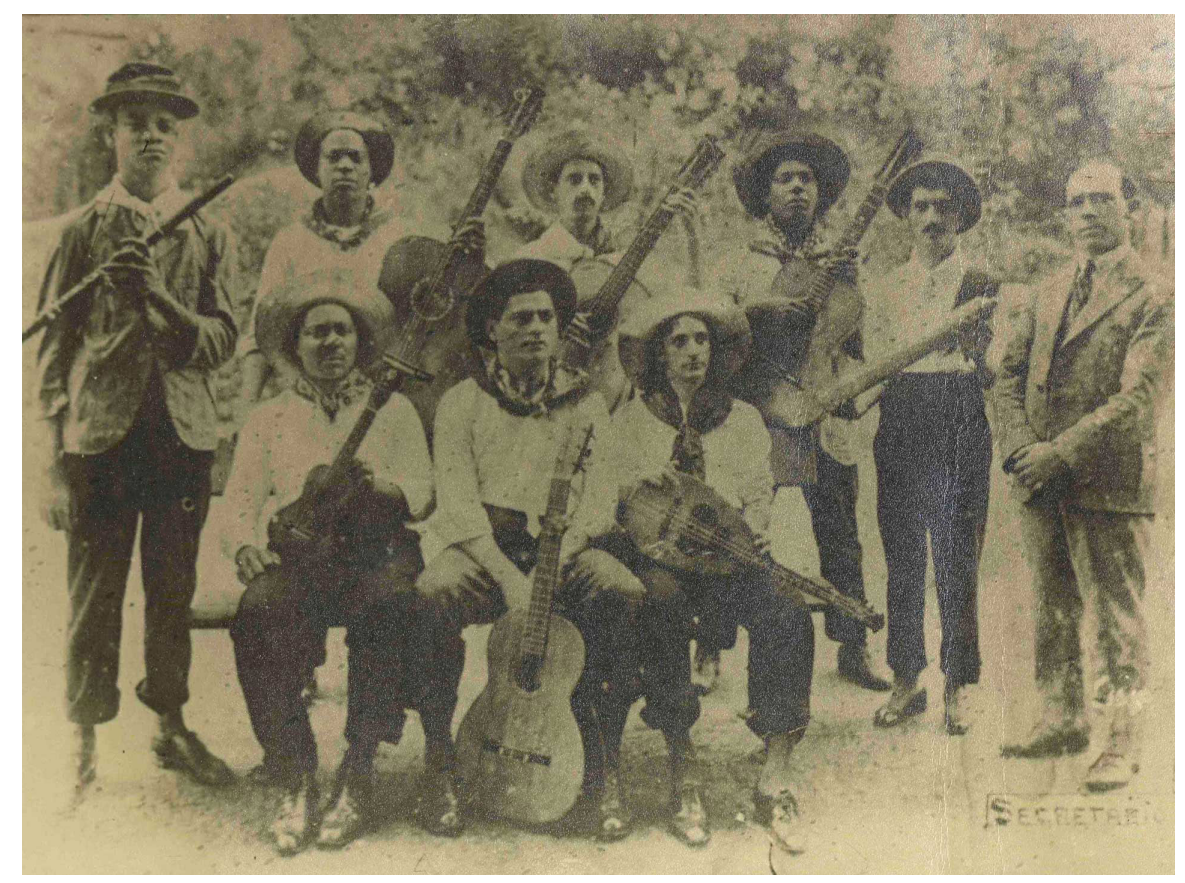

Figura 2: Os Oito Batutas com figurino nordestino (foto de 1920)

Fonte: www.pixinguinha.com.br

Apresentavam-se inicialmente em populares casas de chope e nas salas de espera de cinemas de classe média na cidade e, nesses últimos, sofriam preconceitos por serem negros. Em 1922, são convidados por Duque, bailarino baiano erradicado em Paris, a fazerem uma temporada no dancing que este administrava, o Shéhérazade, como mencionamos no início deste trabalho. Segundo o próprio Pixinguinha, o reconhecimento em Paris resultou, ao retornarem ao Brasil em uma maior aceitação do grupo, com mais convites para tocar (citado por Bessa, 2010, p. 176). Tal viagem influenciou de maneira definitiva a carreira, a performance e a musicalidade dos Batutas e de Pixinguinha. Bessa observa que

em Paris, os brasileiros notaram que sua música era consumida como exótica - e portanto, como moderna. Essa percepção se refletiu, por exemplo, no repertório do grupo, que passou a incluir gêneros estrangeiros em suas 
apresentações, tais como o foxtrote, o shimmy e o ragtime. A mudança transpareceu, ainda, na vestimenta dos músicos, que abandonaram definitivamente os trajes nordestinos, aderindo ao terno escuro ou ao smoking. Novos instrumentos foram adicionados ao antigo regional, entre eles a bateria de João Tomás, o banjo de China e o saxofone de Pixinguinha, todos provenientes da música de jazz em Paris. A performance também foi alterada, os músicos se posicionando mais descontraída e informalmente no palco. (Bessa, 2010, p. 177)

$\mathrm{Na}$ pesquisa inicial que desenvolvemos, encontramos alguns registros da passagem de Les Batutas, como eram chamados na França, e de Pixinguinha. No registro fotográfico seguinte (Figura 3), Pixinguinha (à esquerda) ainda não trocou a flauta (seu instrumento principal até então) pelo saxofone (por influência dos grupos de jazz), a bateria de João Tomás ainda não aparece aqui, mas percebemos o banjo nas mãos de José Alves de Lima e a mudança no figurino do grupo mencionada por Bessa (2010), o que aproxima Les Batutas dos grupos de jazz que se apresentavam em Paris.

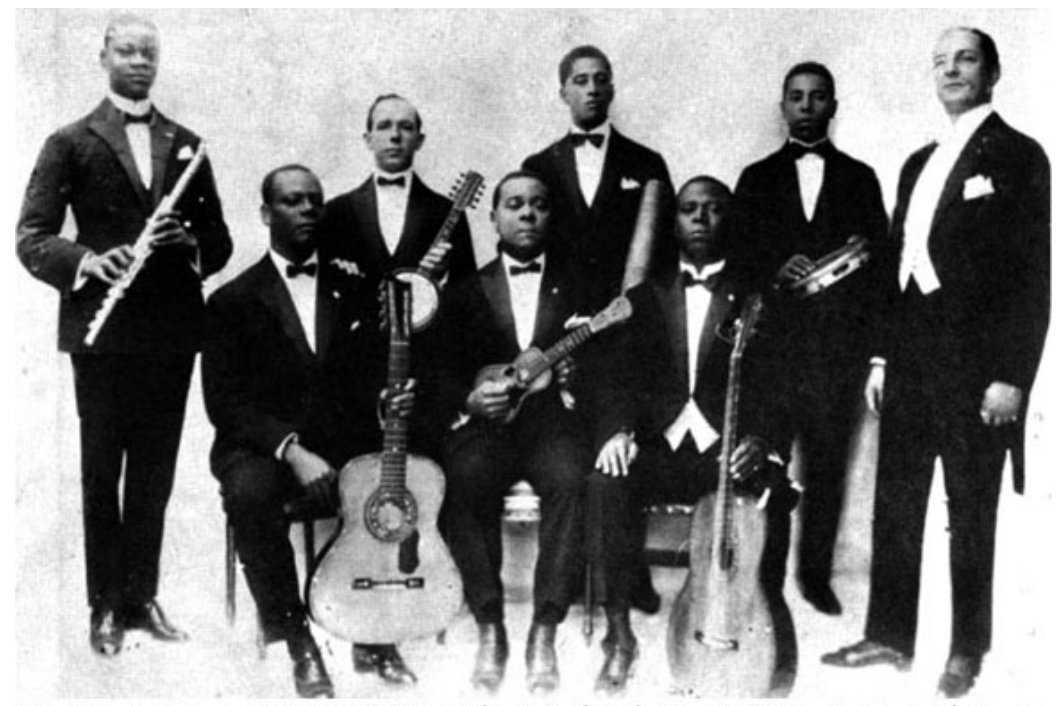

"Les Batutas" e Duque, 1922. Em pé: Pixinguinha, José Alves de Lima, José Monteiro, Sizenando Santos "Feniano" e Duque. Sentados: China, Nelson dos Santos Alves e Donga.

Figura 3: Les Batutas e Duque em Paris (1922)

Fonte: Bastos, 2017

Além de campanhas veiculadas em jornal, encontramos também catálogos de empresas de gramofone que demonstram que os músicos registraram em discos algumas canções (Figuras 4 e 5). 


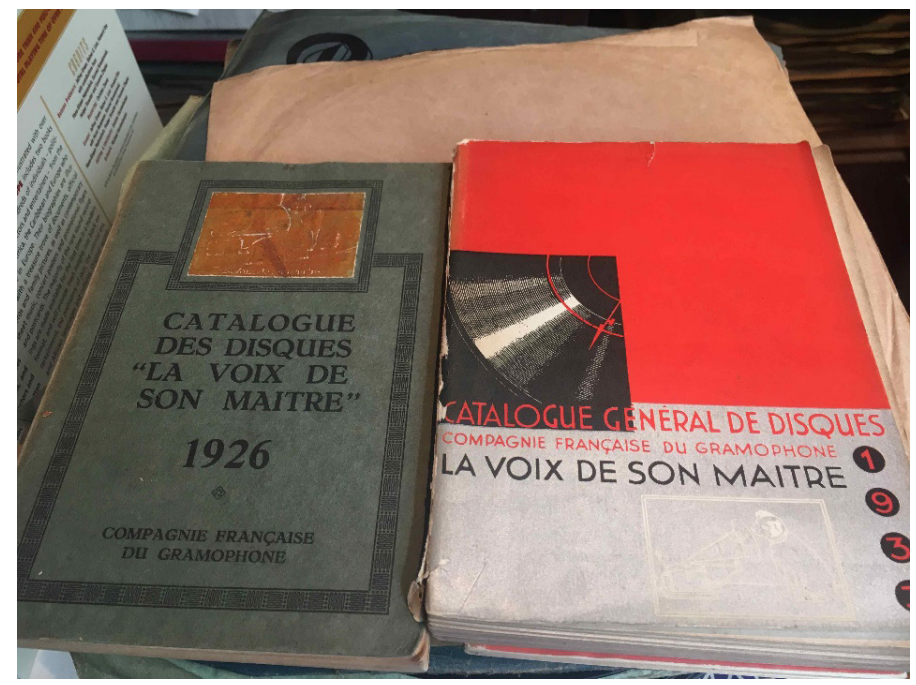

Figura 4: Catálogos gerais de discos da Compagnie Française du Gramophone (1926 e 1933)

Fonte: Registro fotográfico da autora a partir do acervo do Phonomuseum (Paris)

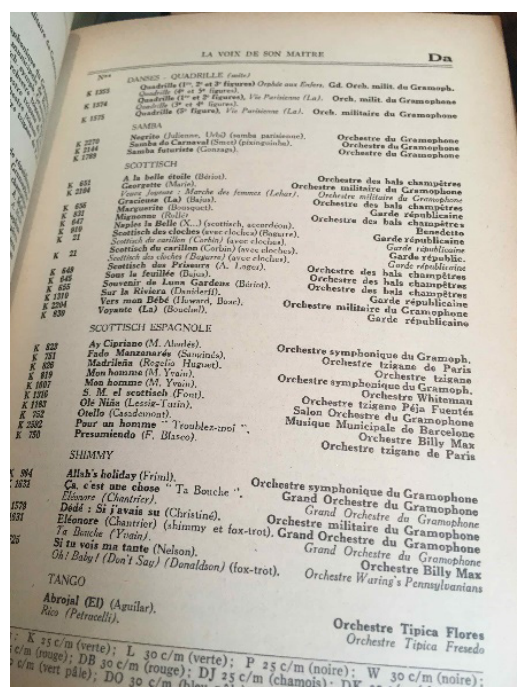

\footnotetext{
Figura 5: Catálogo do ano de 1926 da Compagnie Française du Gramophone. Menção ao registro de uma canção de Pixinguinha ( ${ }^{\mathrm{a}}$ linha do gênero Samba)
}

Fonte: Registro fotográfico da autora a partir do acervo do Phonomuseum (Paris)

Alguns historiadores registram a composição em francês que Pixinguinha fez juntamente com Duque durante a temporada no Shéhérazade. A canção servia como um "cartão de visitas", uma apresentação do grupo:

Nous sommes batutas

Batutas, Batutas

Venus du Brésil

Ici tout droit

Nous sommes Batutas

Nous faisons tout le monde

Danser le samba (Lira Neto, 2017, p. 120) 
Deve-se notar que nesses primeiros registros de samba em Paris, o gênero musical era apresentado como no Brasil no masculino - le samba. Mais tarde, ao se popularizar, o samba na França passa a ser apresentado no feminino - la samba - a fim de ter um apelo comercial, ao soar assim mais natural na língua francesa (Jacotot, 2013).

Não foi por acaso que Pixinguinha e os Batutas fizeram tal viagem a Paris. Paris desde o século XIX era uma referência para a cultura brasileira. Como apresentamos em um trabalho anterior ${ }^{5}$, ainda que a corte portuguesa tenha fugido para o Brasil por causa da ameaça da invasão francesa por Napoleão no início do século XIX, como defendia Benjamin, Paris era considerada a capital cultural daquele século. Assim, ainda que ameaçada pelos franceses, a corte portuguesa tinha como modelo essa Paris capital para moldar as novas instituições criadas no Brasil.

A canção popular brasileira, produto cultural marcado pela intermidialidade, ao ser colocada em circulação por meio de shows, de discos, do rádio, do cinema e do teatro de revista a partir do início do século XX nos desvela traços dessa referência francesa moldada desde o século anterior. Paris é apresentada nas canções que analisamos no trabalho anterior mencionado, como o lugar dos estudos, do divertimento, do consumo de luxo e do amor. No entanto, observamos também em tal trabalho que tais imagens fazem parte de uma narrativa complexificada, uma vez que percebemos nos pastiches da língua francesa (que são mais numerosos que o uso correto do francês, sendo o caso da canção de Duque e Pixinguinha uma exceção, uma vez que foi feita para circular originalmente nos dancings em Paris) ou nas escolhas dos sujeitos das canções que, ao conhecerem Paris, ainda que se encantem pela cidade, preferem o Brasil. Nesses casos, apesar do encanto pela capital francesa, o nacionalismo predomina. Assim, a cultura francesa é identificada como algo próximo das elites e distante do popular, do "verdadeiramente" brasileiro. Nesses casos, a cultura francesa parece servir apenas como uma escada para valorizar o próprio Brasil. A vida boêmia em Paris pode ser incrível, mas o sujeito da canção prefere a praia do Leme no Rio de Janeiro, como acontece na canção Paris (composição de Vermelho e Alcyr Pires, 1938). Ou como na canção Fui a Paris (Moreira da Silva/Ribeiro Cunha, de 1942), em que o cancionista vai tocar em Paris, onde encontra o amor, mas prefere o amor carioca. Tal samba poderia ser inspirado na passagem de Pixinguinha e os Batutas por Paris, que, apesar de se encantarem pela cidade e inclusive arranjarem namoradas por lá (Lira Neto, 2017) como o sujeito da canção, retornam depois de alguns meses ao Rio de Janeiro.

Da mesma forma, o samba deixou marcas na cultura francesa e, assim como os sambistas assimilaram influências do jazz que circulava em Paris, os musicistas e intérpretes de jazz também assimilaram elementos da cultura brasileira por meio dos sambas que chegavam a Paris. Vários artistas na França cantaram o Brasil. Em 1949, a própria Josephine Baker, erradicada na França desde a década de 1920, cuja chegada em Paris trataremos a seguir, grava na França o samba $O$ que é que a baiana tem ${ }^{6}$, um clássico do cancioneiro popular brasileiro.

\footnotetext{
${ }_{5}^{5}$ Comunicação oral apresentada em um seminário do programa de pesquisa PIMI (Patrimoine- Image- Média- Identité) em 2017 a ser publicada futuramente nos anais do evento.

${ }^{6}$ Composição de Dorival Caymmi de 1939, gravado originalmente por Carmem Miranda no mesmo ano.
} 


\section{Mon paYs et PARIS}

Um dos marcos da transformação da paisagem sonora parisiense do período entre-Guerras e da presença do jazz no período entre-Guerras na França é a chegada de Josephine Baker e sua trupe de jazz a Paris em 22 de setembro de 1925.

O seu primeiro espetáculo de sucesso logo na sua chegada em Paris - o teatro de revista la Revue Nègre (Revista Negra) - deveria ser apresentado apenas por duas semanas no Théâtre des Champs Elysées. No entanto, ainda que os franceses já conhecessem o jazz, o espetáculo se torna uma coqueluche entre os parisienses, se torna o principal acontecimento artístico do ano de 1925 e fica em cartaz durante dois meses.

A artista norte-americana fica impressionada com a liberdade francesa dos costumes logo em sua chegada. Em seu espetáculo, Josephine Baker é acompanhada por um grupo de jazz e dança um Charleston endiabrado. Aparece quase nua em cena, o que contrasta com a sua aparição em um vestido de Paul Poiret, famoso costureiro da época, de braços dados com Paul Colin, logo após o espetáculo (Labiausse`). Pela primeira vez, o corpo negro é publicizado em cena e fora de cena como modelo de beleza e a música negra, por sua vez, é valorizada como algo moderno:

este espetáculo, que impulsiona Josephine Baker ao sucesso, também torna o artista Paul Colin uma celebridade, este que soube colocar em seu cartaz a modernidade da trupe de Nova York que acompanha Baker. O espetáculo marca o início da "folie noire", feita de jazz, de Charleston e de excentricidades diversas que invadiu Paris e conduzirá inúmeros artistas negros à se instalarem na França para fugir das tensões raciais dos Estados Unidos (Bachollet \& Lelieur, 1992, p. 136)

A chamada "folie noire" toma conta dos novos espaços de dança da época - os dancings - e passa a fazer parte de maneira regular dos music halls, por meio de teatros de revista. Josephine Baker, por sua vez, se torna um símbolo da liberação feminina. Conforme refere Labiausse,

com suas atitudes claramente modernas, ela contribuiu para acelerar essa revolução [feminina], carregando-a como um símbolo. Na Paris dos anos 1920, o nome de Josephine é sinônimo de liberdade. Com seus seios pequenos, suas ancas desnudas, seus cabelos pretos cortados curtos e colados com goma, Josephine encarnava um grande número de tendências, gostos e aspirações da época. Ela não era mais uma pessoa, mas sim um conceito e se tornou a "garçonne" típica, aquela do célebre romance de Victor Margueritte. (Labiausse ${ }^{8}$ )

Josephine parte em tournée para Bruxelas e Berlim, onde alcança grande sucesso entre os alemães. Volta a Paris onde faz espetáculos no Folies Bergère e monta um dancing onde vai dançar após as noites de espetáculo. Montparnasse se torna um bairro de

\footnotetext{
7 Ver http://migrateurs-transatlantique.pagesperso-orange.fr/josephine_baker.htm

${ }^{8}$ Ver http://migrateurs-transatlantique.pagesperso-orange.fr/josephine_baker.htm
} 
Paris que abriga intelectuais e artistas franceses e americanos e um incontável número de dancings onde se ouve e se dança as músicas das Américas. A partir do impacto das suas apresentações, ela se torna a musa de artistas avant garde, célebres frequentadores dos dancings. Como elenca Labiausse:

ela cativa os mestre da época: o pintor Foujita suplica que ela pose para ele. Ela posaparaPicasso, Van DongeneHorst, nuapara Dunande Man Rayafotografa. $O$ cubista Henri Laurens a representa dançando o charleston. Em 1926, Alexandre Calder faz uma caricatura dela em fios de ferro, assim como várias esculturas. O mais célebre retrato de Josephine é um nu de Jean-Gabriel Domergue: ela está sentada, inclinada para frente, com os lábios úmidos e uma flor branca nos cabelos. Este quadro, que a princípio foi exposto no Grand Palais em Paris, foi reproduzido em cartões postais. Os escritores a homenageavam. Francis Scott Fitzgerald a menciona em uma de suas novelas, Retorno à Babilônia; (...) Maurice Sachs evoca Josephine na sua obra Nos tempos do Boeuf sur le Toit, que conta a vida mundana do autor sob forma de diário: "Charleston: Foi Josephine Baker quem lançou com os negros no music-hall de Champs Elysées. Cat's Wisker. Este charleston universal substituiu o blues e o shimmy." Colette a qualifica de "a mais bela pantera" e Erich Maria Remarque se refere à Josephine como aquela que "trouxe um ar da selva, da força e da beleza elementares para os palcos cansados da civilização do oeste." E foi Josephine que inspira Paul Morand a escrever seu romance Magia Negra. Morand via Josephine como uma maquina de dança, alimentada por uma energia primitiva. Ela correspondia à sua concepção da selvagem incansável, cheia de alegria, cujo espírito era desprovido de complicações. A mais bonita homenagem feita à Revue Nègre e à Josephine em Paris nos Anos Loucos foi realizada por Paul Colin que se apropria dos dançarinos para produzir uma série de desenhos onde ele jogava com a força e o dinamismo das cores. 45 litografias foram reunidas em um álbum intitulado Tumulto Negro e editado em 1927. (Labiausse9)

Em nossa pesquisa preliminar, encontramos alguns dos antigos endereços de tais estabelecimentos frequentados pelos artistas e notívagos anônimos em Montparnasse. Fizemos um percurso a pé entre eles (para fazer registros fotográficos das fachadas dos endereços que abrigavam os dancings), o que nos confirma a proximidade entre os dancings, o que permitia que os notívagos mudassem de estabelecimento para ouvir músicas diferentes ao longo da noite, como nos descrevem alguns pesquisadores do período (Jacotot, 2013).

Em 1930, Josephine grava um de seus sucessos pelos quais ainda hoje, mesmo após a sua morte em 1975, é lembrada: J'ai deux amours $^{10}$.

\footnotetext{
${ }^{9}$ Ver http://migrateurs-transatlantique.pagesperso-orange.fr/josephine_baker.htm

10 "J'ai deux amours" interpretada por Joséphine Baker (letra: Géo Koger, H. Varna, música: Vincent Scotto -1930)
} 


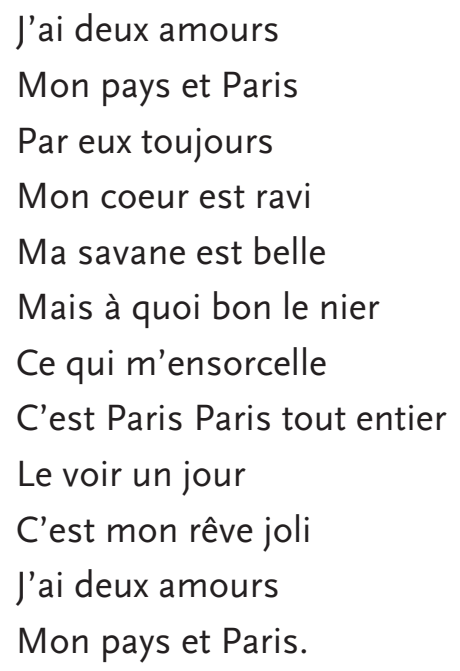

Apesar de não ser de autoria de Baker, a letra da canção parece autobiográfica. $O$ sujeito da canção, diz ter dois amores "meus país e Paris". Esse amor se divide entre a origem norte-americana da artista e suas raízes africanas - uma vez que a letra fala de "savanas", imagem recorrente nas representações do continente africano - e o seu novo "país" - a capital francesa. Como diz a letra, a savana do seu país é bela, mas o que a encanta é Paris.

Essa dubiedade se apresenta também na performance da voz versus a letra da canção. A artista canta em francês correto, no entanto, também carrega em sua performance as marcas de sua origem: o sotaque americano. É diferente do que acontece com as canções brasileiras da época que têm Paris como referência. Como mencionamos, a maior parte dos cancionistas brasileiros que compuseram canções que fazem referência a Paris o fizeram em Português e não na língua francesa. O Francês é utilizado em forma de pastiche nas letras e na pronúncia dos intérpretes, que não fazem nenhum esforço no sentido de uma pronúncia correta da língua. Além disso, apesar de Paris ser considerada uma referência para a cultura no mundo, os sujeitos das canções, em geral, preferem - Brasil e especialmente a cidade do Rio de Janeiro. Assim, Paris é encantadora, mas o sambista prefere o amor do Rio, ao contrário de Josephine Baker que escolheu a França como lar e só voltava ao seu país de origem para fazer shows eventuais.

Ainda que tenha gravado diversas canções cuja musicalidade se aproxima da tradição da chanson française (como diversas versões de J'ai deux amours) o que tornou a chegada de Baker um acontecimento marcante na vida cultural da cidade foi a sua performance endiabrada ao dançar o Charleston ao som do jazz, os seus figurinos (e por vezes, a falta deles, ao dançar seminua), a sua "adoção" pelos artistas e intelectuais avant-garde da época, encantados pela beleza e exotismo dos corpos negros e pela sonoridade das músicas de origem além-mar, cujas marcações rítmicas pediam o envolvimento do corpo nas performances, sejam de samba, sejam de Charleston e de outras danças derivadas do jazz. 


\section{À guisa de CONClusão: QUeSTÕes E PERCURSOS FUtURos}

O panorama da chegada do samba e do jazz na Europa e das transformações das paisagens textuais europeias no período entre-Guerras, motivou-nos, no ano do centenário do primeiro registro do samba e do primeiro registro do jazz, a propor uma pesquisa pós doutoral que tem como objetivo principal entender as representações- síntese do Brasil e dos EUA na Europa por meio do jazz, do samba e das danças originárias desses gêneros musicais relacionadas às transformações ocorridas na paisagem textual urbana no período entre-Guerras. Na primeira metade do século $X X$, a música brasileira e a música americana se fazem presentes em Paris, capital cultural do século XIX, como defendia Walter Benjamin. Como observamos no artigo, a capital francesa também se faz presente nas canções cantadas por brasileiros e norte-americanos.

Pires (2014) defende que "entendida a cidade como um palco que se presta ao desfile das transformações mais visíveis operadas na paisagem pela modernidade, importa interrogar as suas diversas representações, isto é, o modo como no nosso imaginário Paris, Londres, Nápoles ou Nova lorque, se tornam lugares frequentemente revisitados" (Pires, 2014, p. 277) . Assim, os resultados preliminares da pesquisa apresentados aqui sugerem uma imbricação entre as transformações na paisagem urbana textual de Paris e a chegada das novas músicas das Américas, incluindo nesta paisagem, os cartazes, as fachadas dos estabelecimentos, a moda e o figurino dos artistas e a musicalidade destes relacionadas a seus países de origem. Concordamos com La Rocca (2010) que busca entender as cidades a partir de uma "climatologia sociológica e cultural" que observa, a "temperatura social", os "ventos culturais", das "precipitações simbólicas", das "nuvens estéticas" que pairam sobre as cidades em determinados tempos. De acordo com essa visada, "por conseguinte, o tempo contrai-se em espaço, conferindo assim um novo significado, uma nova acentuação da espacialidade. Espacialidade essa que poderia ser denominada de 'imaginal', e que contribui para a acentuação do presente" (La Rocca, 2010, p. 161).

Pretendemos assim, em uma próxima etapa da pesquisa, cartografar os lugares que receberam as músicas das Américas, fazendo uma pesquisa das localizações originais no início do século $X X$, além de registros fotográficos a fim de compreender os rastros daquele tempo passado no espaço presente da cidade. Mas, mesmo antes de desenvolvermos essa cartografia, os achados iniciais da pesquisa que apresentamos aqui nos colocam algumas questões a serem respondidas ao longo do desenvolvimento do projeto: como seriam essas representações que sintetizam supostas identidades coletivas que inicialmente não são aceitas nem mesmo nos próprios países de origem? Que imagens do Brasil e dos Estados Unidos essas representações evocam? Em que medida as transformações na paisagem textual urbana de Paris a partir dos novos dancings e music halls franceses se relacionam às novas músicas das Américas? Quais são os rastros dessa paisagem textual do período entre guerras na paisagem contemporânea urbana atual em Paris?

Além de buscar responder a essas questões, o projeto aponta ainda para pesquisas futuras, como por exemplo, entender como os músicos são recebidos quando regressam 
aos seus países de origem, observando indícios do reconhecimento alcançado na Europa como uma forma de legitimação de tais gêneros, inicialmente rejeitados em seus próprios países.

Nos tempos atuais, em que o fundamentalismo, a xenofobia e o racismo estão em pauta, em um momento em que países como o Brasil assistem a uma virada política e social à direita acompanhada de uma crescente intolerância com o outro, consideramos relevante compreender os processos de afirmação das minorias negras e de consolidação de gêneros musicais de origem negra como conformadores de identidades nacionais em um país europeu distante. Em outras palavras: buscamos a compreensão daqueles "ventos culturais" originários das Américas, que sopraram sobre o continente europeu no período entre-Guerras e geraram "precipitações simbólicas" significativas ainda hoje, no tempo presente.

\section{REFERÊNCIAS BIBLIOGRÁFICAS}

Abril, G. (2007). Análisis crítico de textos visuales. Madrid: Editorial Sintesis.

Bachollet, R. \& Lelieur, A. C. (1992). Negripub. Paris: Somogy.

Bastos, R. J. M. (2005). Les Batutas, 1922: uma antropologia da noite parisiense. Revista Brasileira de Ciências Sociais, 20(58), 177-196. Retirado de https://tinyurl.com/yct3u6fk

Bessa, V. A. (2010). Imagens da escuta: traduç̃es sonoras de Pixinguinha. In J. G. V. Moraes \& E. T. Saliba (Eds.), História e música no Brasil. (pp. 163-216). São Paulo: Alameda.

Cohen, E. (1999). Paris dans l'imaginaire national de l'entre-deux-guerres. Paris: Publications de la Sorbonne.

Dorier-Apprill, E. \& Apprill, C. (2000). Ces danses qu'on dit "latines". In E. Dorier-Apprill (Ed.), Danses "latines" et identité, d'une rive à l'autre (pp. 11-17). Paris: L'Harmattan.

Garandeau, V. (1998). Du cake-walk au rock'n roll: le bal sous influence jazz. In Y. Guilcher (Ed.), Histoires de bal: vivre, représenter, recréer le bal (pp. 105-116). Paris: Cité de la Musique.

Hobsbawm, E. J. (1990). História social do jazz. São Paulo: Paz e Terra.

Jambeiro, O. (2004). Tempos de Vargas: o rádio e o controle da informação. Salvador: EDUFBA.

Jacotot, S. (2013). Danser à Paris dans l'entre-deux-guerres. Lieux, pratiques et imaginaires des danses de société des Amériques (1919-1939). Paris: Nouveau Monde éditions.

La Rocca, F. (2010). Ambiências climatológicas urbanas: pensar a cidade pós-moderna. Comunicação e Sociedade, 18, 57-164. doi: 10.17231/comsoc.18(2010).994

Lira Neto. (2017). Uma história do samba: volume I (As origens). São Paulo: Companhia das Letras.

Luchiari, M. T. D. P. (2001). (Re)significação da paisagem no período contemporâneo. In Z. Rosendhal \& R. L. Corrêa (Eds.), Paisagem, imaginário e espaço (pp. 9-28). Rio de Janeiro: EDUERJ.

Manning, S. (2009). Danses noires, Blanche Amérique. Paris: Centre National de Danse.

Muniz Sodré. (1998). Samba, o dono do corpo. Rio de Janeiro: Mauad. 
Pires, H. (2014). A paisagem urbana e a publicidade de moda. Comunicação e Sociedade, 26, 275-290. doi: $10.17231 /$ comsoc.26(2014).2039

Tatit, L. (2004). O século da canção. Cotia: Ateliê Editorial.

Teixeira, M. D. M. (2012). Mundanismo, transgressão e boémia em Lisboa dos anos 20 - o clube noturno como paradigma. Monografia de Conclusão de Licenciatura em História. Universidade Lusófona de Humanidades e Tecnologias, Lisboa, Portugal.

Tinhorão, J. R. (1981). Música popular: do gramofone ao rádio e TV. São Paulo, Ática.

Weill, A. (2013). L'affiche Art Déco. Paris: Hazan.

Vaz, P. B. F., Mello Vianna, G. \& Santos, H. (2017). Sobre texto visual, sonido e imagen: nuevos parajes de los paisajes textuales In B. Leal, C. A. Carvalho \& G. Alzamora (Eds.), Textualidades mediáticas (pp. 131-150) Barcelona: Editorial UOC.

\section{Financiamento}

Para o desenvolvimento de parte da pesquisa pós-doutoral da qual o presente artigo apresenta resultados preliminares, foi solicitado ao Conselho Nacional de Desenvolvimento Científico e Tecnológico (CNPq), agência do Ministério da Ciência, Tecnologia, Inovações e Comunicações (MCTIC) no Brasil, financiamento por meio do edital do CNPq Pós-Doutorado no Exterior 2018. Foi solicitado também no Brasil financiamento à Coordenação de Aperfeiçoamento de Pessoal de Nível Superior (Capes) no edital para professor visitante no exterior de 2018. Na ocasião do envio do texto final do presente artigo, ainda aguardávamos os resultados das solicitações a tais agências de fomento para dar continuidade ao projeto.

\section{NOTAS BIOGRÁFICA}

Graziela Mello Vianna (UFMG - Brasil) é Doutora em Comunicação pela Escola de Comunicações e Artes da Universidade de São Paulo (ECA-USP). Professora Adjunta do Departamento de Comunicação Social da Universidade Federal de Minas Gerais (Brasil) onde coordena o grupo de pesquisa e extensão GRISsom e leciona disciplinas relacionadas ao som, ao rádio, à linguagem sonora, às paisagens urbanas e à memória. Publicou recentemente o livro Imagens sonoras no ar: a sugestão de sentido na publicidade radiofônica. Atualmente, desenvolve pesquisa de pós-doutoramento na França e em Portugal.

E-mail: grazielavmv@gmail.com

Morada: Rua Divinópolis, 313 ap.401, CEP 31010-370, Belo Horizonte / MG (Brasil)

* Submetido: 30-11-2017

* Aceite: 15-02-2018 